NASA Technical Memorandum 83594

\title{
Impact Resistance of Fiber Composites: Energy Absorbing Mechanisms and Environmental Effects
}

C. C. Chamis and J. H. Sinclair

Lewis Research Center

Cleveland, Ohio

Prepared for the

Second United States/Japan Conference on Composite Materials: Mechanics, Mechanical Properties, Processing Science and Technology, and Applications ? Hampton, Virginia, June 6-8, 1983

\section{N/Sก}




\section{CONTENTS}

Page

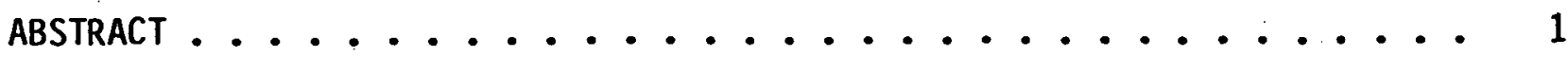

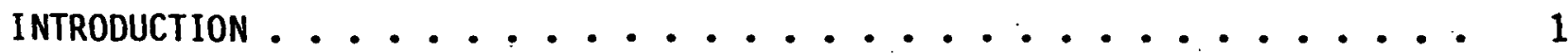

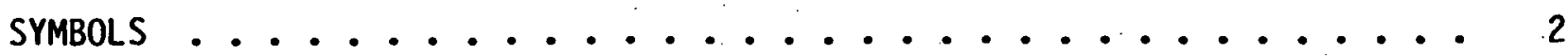

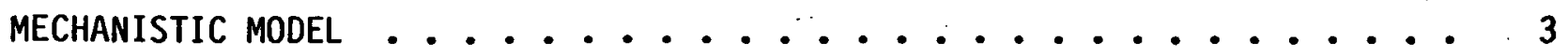

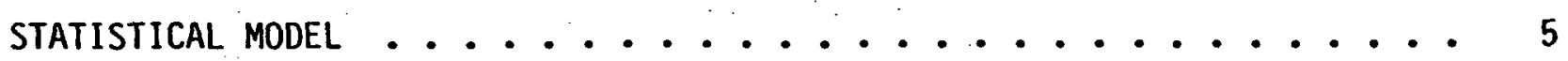

TRANSIENT FINITE-ELEMENT ANALYSIS ................ 6

INDIVIDUAL-LAYER-BEAM BEHAVIOR AND FRACTURE PROGRESSION . . . . . 7

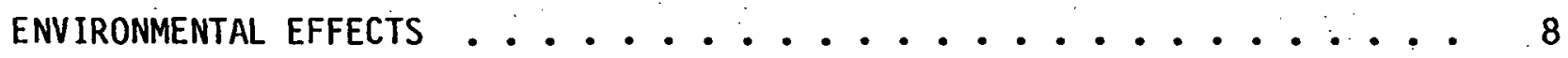

GENERALIZATIONS AND PROPOSED DEFINITIONS .............. 9

SUMMARY OF RESULTS AND CONCLUSIONS ....................... 10

APPENDIX - ILLUSTRATIVE EXAMPLE OF ENVIRONMENTAL EFFECTS

ON IMPACT RESISTANCE ........................... 11

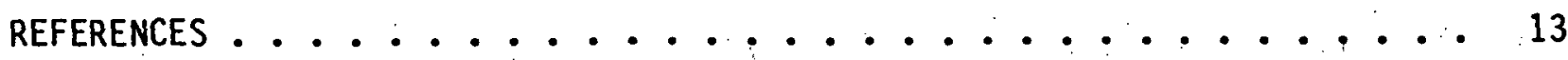


IMPACT RESISTANCE OF FIBER COMPOSITES:

\title{
ENERGY-ABSORBING MECHANISMS AND ENVIRONMENTAL EFFECTS
}

\author{
C. C. Chamis and J. H. Sinclair \\ National Aeronautics and Space Administration \\ Lewis Research Center \\ Cleveland, Ohio 44135
}

\begin{abstract}
Energy-absorbing mechanisms are identified and evaluated using several approaches. The energy-absorbing mechanisms considered are those in unidirectional composite beams subjected to impact. The approaches used include mechanistic models, statistical models, transient finite-element analysis, and simple beam theory. Predicted results are correlated with experimental data from Charpy impact tests. The environmental effects on impact resistance are also evaluated. Working definitions for energy-absorbing and energy-releasing mechanisms are proposed and a dynamic fracture progression is outlined. Possible generalizations to angleplied laminates are described:
\end{abstract}

\section{INTRODUCTION}

Fiber composites have several attractive design attributes for use in structures and structural components." In addition to the well-known high strength and stiffness to density ratios, fiber composites exhibit high tensile fatigue resistance, notch insensitivity, ease of fabrication, and low scrap rate. Furthermore, fiber composites provide the unique opportunity to simultaneously optimize structural configuration, material makeup, fabrication process, and structural integrity. On the other hand, fiber composites have some disadvantages which include complex constitutive relationships, coupled structural responses, relatively high material cost, moisture degradation, and low impact resistance. Mechanisms contributing to low impact resistance are receiving considerable research attention (refs. 1 to 4 ).

There is still no general consensus in the composites community as to what constitutes energy-absorption mechanisms relative to impact. The lack of consensus arises, in part, from the difficulty of identifying and quantifying the multitude of mechanisms in which composites fail and through which composites absorb energy during impact. This multitude of failure or energyabsorption mechanisms includes micromechanics mechanisms, such as fiber and matrix fractures, intra- and interlaminar shear delaminations, fiber pullout, and local indentation. The difficulty in achieving a consensus is further compounded by a school of thought which advocates that the energy release rates of fracture surfaces associated with fracture modes I, II, and III are related to some energy-absorption mechanisms for composite impact resistance.

The objective of this paper is to evaluate the significance of various mechanisms contributing to impact resistance using mechanistic models, statistical models, transient finite-element analysis, and simple beam analysis associated with the Charpy impact tests and data. The hygrothermal effects on composite impact resistance are also evaluated. 


\section{SYMBOLS}

C

$\mathrm{d}_{\mathrm{f}}$

E

Ep

G

h

IED

k

e

$N$

$N_{\ell} 0$

$\mathrm{S}$

$\mathrm{T}$

$V_{0 I}$

$X, Y, Z$

$1,2,3$

$\delta$

$\sigma$

unknown coefficients in statistical model; subscripts 1 to 5 correspond to five terms in equation

fiber diameter.

modulus

undegraded modulus

shear modulus

beam thickness

impact energy density $\left(\mathrm{in}-1 \mathrm{~b} / \mathrm{in}^{3}\right.$ or $\left.\mathrm{ft}-1 \mathrm{~b} / \mathrm{ft}^{3}\right)$

volume ratio

length

number of individual layers

number of delaminated layers

property subscript define reference

strength, subscripts define material type and direction and sense

temperature subscripts define reference

local damage volume

work done, beam width

structrual axis coordinates

material axis coordinates

beam deflection

stress; subscripts denote type, direction and sense

\section{Superscripts:}

a average through-the-thickness

$s \quad$ surface ply properties

Subscripts:

$\begin{array}{ll}\text { C } & \text { compression } \\ \text { C } & \text { core property, composite property } \\ \text { F } & \text { flexural } \\ \text { FC } & \text { composite flexure } \\ \text { FN } & \text { individual beam layer flexure } \\ f & \text { fiber property } \\ \text { fd } & \text { fibers pulled out } \\ \text { gd } & \text { glass transition, dry } \\ \text { gW } & \text { glass transition, wet } \\ \text { H } & \text { hygrothermally degraded property } \\ \ell & \text { ply property } \\ N & \text { individual layer beam } \\ S & \text { shear } \\ \text { SC } & \text { composite shear } \\ \text { T } & \text { tension } \\ 0 & \text { reference property } \\ 1,2,3 & \text { material axis coordinate directions } \\ \text { Conversion } & \text { factors of units used in text: } \\ 1 \mathrm{ft}-1 b & =1.35 \text { Joules } \\ 1 \text { in. } & =2.54 \text { cm }\end{array}$



1 in. $2=6.5 \mathrm{~cm}^{2}$
1 in. $=16.4 \mathrm{~cm}^{2}$
1 in-1b $=0.112$ Joules
$1 \mathrm{ksi}=6.9 \mathrm{MPa}$
$1 \mathrm{lb} \quad=4.45 \mathrm{~N}$
$1 \mathrm{lb} / \mathrm{in}^{3}=27.7 \mathrm{gm} / \mathrm{cm}^{3}$
$1 \mathrm{psi}=6.9 \mathrm{kPa}$

\section{MECHANISTIC MODEL}

The mechanistic model for the assumed energy-absorption mechanisms was derived using elementary beam theory in conjunction with the composite mechanics procedures described in references 1 and 5 . The beam schematic used, the boundary conditions, and the resulting equation for impact energy density (IED) are summarized in figure 1. The coefficient representing the. energy-absorption mechanisms included in the IED equation (assuming a. unidirectional composite with fibers aligned parallel to the $x$-axis) are as follows:

(1) Area under the stress strain curve, $s_{\ell 11 T}^{(s) 2} / 2 E_{\ell 11}$, where $s_{\ell}^{(s)}$ represents the tensile strength on the surface $p l y, E_{\ell}$ the corresponding modulus, numerical subscripts 11 the direction, and subscript $T$ the tension.

(2) Flexural bending, $1 / 9$.

(3) Interlaminar shear, $(1 / 7.5) \times(\mathrm{h} / \mathrm{l})^{2} \times\left(\mathrm{E}_{\ell 11}^{(\mathrm{a})} / \mathrm{G}_{\ell 11}^{(\mathrm{a})}\right)$, where the super scripts a denotes integrated averages for $E$ and $G$ and where $G_{\ell 11}$ is the interlaminar shear modulus. (The interlaminar shear modulus equals the intraiaminar shear modulus for undirectional composities.)

(4) Delamination, $\left(N_{\ell D} / 8\right) \times(h / l) \times\left(E_{\ell 11}^{(s)} / S_{\ell 12 S}^{(c)}\right)$, where $N_{\ell D}$ denotes the number of delaminated layers and $S_{\ell}(c)$ denotes the interlaminar shear strength of the respective delaminated layer at the core of the beam.

(5) Fiber pullout, $(1 / 2)\left(k_{f D}\right) \times\left(d_{f} / \ell\right) \times\left(E_{\ell 11}^{(s)} / S_{\ell 12 S}^{(s)}\right) \times\left(S_{f T}^{(s)} / S_{\ell 11 T}^{(s)}\right)^{2}$; where $k_{f D}$ denotes the fiber pullout volume ratio, $d_{f}$ the fiber. diameter, superscript s the surface plies or plies failing by longitudinal tension, and $S_{f T}$ the respective fiber tensile strength.

(6) Inelastic energy (INEL. ENERGY) associated with transverse splitting and local indentation is roughly proportional to $V_{D I} S_{\ell 22 T}^{2} / E_{\ell 22}$. where $V_{D I}$ is the local damage volume, $S_{\ell 22 T}$ the transverse tensile strength, and $E_{\ell 22}$ the undirectional transverse modulus. 
The $V_{D I}$ and proportionality constant can be determined using an available contact law (refs. 6 and 7). This term may also be expressed as $2 a h S_{\ell 22 C}^{2} E_{\ell 11}^{(s)} / \ell E_{\ell 22} S_{11 T}^{(s) 2}$ where a is the ratio of the indentation area $\delta w$ to the square of the beam thickness $h^{2}$ or $\alpha=\delta w / h^{2}$.

The energy-absorbing mechanisms included in the mechanistic model are those mechanisms which are assumed herein to absorb impact energy prior to any impact load drop (from a current level) that would be observed in the impact load versus time trace. This is a reasonable assumption and is consistent with energy absorbed prior to initial or subsequent damage. Any additional energy absorbed subsequent to initial damage would be indicated by corresponding impact load rise versus time. On the other hand, constant or decreasing impact load versus time indicate release of energy already stored in the composite beam rather than energy absorbed. Each term in the mechanistic model. can be further expressed in terms of constituent material properties using composite micromechanics (refs. 1, 5, and 8).

It is instructive to note that each term in the mechanistic model, including the inelastic energy (item 6) above but excluding the flexural, includes beam length $\ell$ in the denominator. This indicates that for relatively long contact-time impact events the flexural term will present the dominant energy absorbing mechanism since $\ell$ is large compared to the other dimensions. Long contact-time impact events are those in which the shear waves ( $x, y-p l a n e, f i g .1)$ traverse the beam span several times prior to the separa$t$ ion of the projectile from the target. On the other hand, for relatively short contact-time events, the impact resistance is highly localized and the inelastic energy term represents the dominant energy-absorbing mechanism.

Predicted results from the mechanistic model were correlated with Charpy impact data (ref. 9). The geometry of the Charpy test specimen is depicted schematically in figure 2. The constituent material parameters and properties data, used for the correlation, are summarized in table I. These data are for five different composite systems ranging from ultra-high-modulus graphite fiber (T75/EP) to S-glass/epoxy (S-GL/EP). The correlation results for two composite systems are summarized in table II for each energy-absorbing mechanism term in the mechanistic model excluding the inelastic term. This term was excluded from the summary for two reasons: (1) unavailablity of experimental data. (mainly due to difficulty in measuring such data) on each local indentation, and (2) insignificant contribution to the Charpy impact energy compared to the contributions of other terms. For example, if a local indentation one ply deep by one ply wide across the width of the specimen is assumed, the energy absorbed due to this indentation is about 0.001 in-1b for HM/EP composites. This is only 1 :percent of that due to flex $(0.111$ in-lb), which is the smallest contribution in table II.

The following significant points are observed from the results in table II:

(1) The projected combined contribution of all energy-absorbing mechanisms is too high compared to measured values for both composite systems. (about 240 times higher for HM/EP and 30 times higher for S-GL/EP).

(2) The contributions due to flex and shear mechanisms correlate almost exactly with the measured value for the HM/EP composite. 
(3) The flex and shear mechanisms contributions are about one-third the measured value for the S-GL/EP composite.

(4) The interply delamination mechanism contribution is excessively high, even for one delaminated layer, for both composite systems compared to the measured values.

(5) The fiber-pullout mechanism contribution is about 40 percent of the flex-plus-shear contribution for the HM/EP composite and about 120 percent of the corresponding contribution for the S-GL/EP composite.

Based on the correlation of the mechanistic model results with Charpy impact data, the following conclusions are made:

(1) Flex and shear deformations appear to be energy-absorbing mechanisms.

(2) Interply delamination and fiber pullout do not appear to be energyabsorbing mechanisms.

(3) Advanced composites usually fail in a brittle manner under impact once the outer plies have failed in tension or compression.

(4) S-GL/EP composites most likely fail by flexure of progressively delaminated layers (individual beams). This conclusion is supported additionally by the following example. If it is assumed that all the fibers fail in tension above the notch in the Charpy specimens and that a parabolic distribution of stress exists along the specimen span from the notch to the supports (proportional to an approximate specimen displacement shape), the predicted impact energy is about $36.51 \cdot \mathrm{ft}-1 \mathrm{~b}$ compared to the measured value of $35 \mathrm{ft}-1 \mathrm{~b}$. This is too close to be purely coincidental. Furthermore, this conclusion is consistent with the high-speed movie observations (ref. 2).

(5) The area under the unaxial tension/compression stress-strain curve appears to be a reliable quantity for assessing composite energy absorbed under impact which is consistent with findings from previous investigations (refs. 1 and 2).

\section{STATISTICAL MODEL}

The energy-absorption mechanisms were also evaluated using statistical methods in conjunction with multiple linear regression. The statistical model used consists of five terms, which are the same as in the mechanistic model (fig. 1), but each term has an unknown coefficient. The contribution of the inelastic energy due to local indentation is included in this model.

The experimental data used to evaluate the unknown coefficients are summarized in table III (ref. 9). These data include maximum and minimum values for advanced composites, S-glass composites, and two intraply hybrids. At least two specimens were used for each strength or modulus property, and five specimens were used in cases where considerable scatter was observed. Most of the data show a difference of about 10 percent between maximum and minimum values, indicating relatively small scatter from specimen to specimen. Noticeable exceptions are the data for tensile strength of the Modmor II at 47-percent fiber volume and for Charpy impact of the Modmor II at 65-percent fiber volume. Though these data may appear insufficient for statistical analysis, their use is considered justifiable for three reasons:

(1) The data scatter is relatively small, indicating composite uniformity and consistent properties. 
(2) The statistical model used is derivable from the physics of the problem using composite mechanics.

(3) The statistical analysis is pursued primarily to establish the relative significance of each mechanism and thereby to discriminate among energyabsorbing and other mechanisms in a formal, unbiased manner.

The specific statistical analysis used (ref. 10) is in the form of a computer code and is available at the Lewis Computer Center. Inputs to this code are the appropriate data from table III (except the data for the two intraply hybrids) and the statistical model. The outputs include values of the unknown coefficients, the coefficient of correlation, the level of confidence, and the significant (dominant) term retained by the multiple regression. It is noted that the level of confidence is not considered an important parameter in this statistical analysis since the emphasis is on the relative significance of the contribution of each energy-absorbing-mechanism term and not on absolute values.

The form of the statistical model, the dominant term retained by the multiple regression, and the correlation coefficient are shown in figure 3 . Only the flex (elastic bending) term coefficient $C_{1}$ was retained with a correlation value of 0.994 , which is considered very good. This $C_{1}$ value was used to predict the Charpy impact energy for all the composites used in the statistical analysis. It was also used to predict the Charpy impact energy for the two intraply hybrids which were not used in the analysis. The comparisons with measured data are summarized in table IV. The comparisons are excellent.

The most significant conclusion from the statistical analys is is that flexure is the dominant energy-absorbing mechanism in Charpy impact. The contributions of the remaining mechanisms in the statistical model are relatively insignificant and therefore are excluded from being energy-absorbing mechanisms. Additionally, the statistical value of 0.0053 for $C_{1}$ is about five times the corresponding coefficient of 0.00103 for the mechanistic model (table II) in terms of $f t-1 b$. This indicates that flexural fracture of progressively delaminated layers occurs, which is consistent with the conclusion for S-glass/epoxy composite fracture progression mentioned previously. However, it is not consistent with the previous conclusion for the HM/EP (table II). Apparently, the interlaminar shear contribution for the HM/EP composite, and similar composites, appears to be (1) relatively significant if the impact-induced fracture is primarily brittle, or (2) insignificant if the impact-induced fracture is flexural in a progressively delaminated layer. This latter case represents independent beam behavior of each delaminated layer as will be described later.

\section{TRANSIENT FINITE-ELEMENT ANALYSIS}

Transient finite-element analysis of the Charpy impact specimen was performed to assess the possibility of flexural failure of progressively delaminated layers. NASTRAN was used for the finite-element analysis. The required input was obtained from the experimental data (tables I and III). The interlaminar shear-stress variation in the specimen due to a static load was also determined as a part of the transient analysis. The transient analysis was performed using the direct time integration capability of NASTRAN. 
The transient analysis was performed by assuming the specimen remains intact during the impact event. This assumption is reasonable since the interest was on determining the interlaminar shear stress magnitude prior to initial damage. Transient analysis including progressive damage is under current study and well be reported in the future.

The finite-element model and the interlaminar shear-stress contour plot for KEV/EP are summarized in figure 4. The static load of 1810 ib for the interlaminar shear-stress contour plot was selected to produce tensile stress fracture at the notch tip (ref. 11). The interlaminar shear strength for KEV/EP is about $7 \mathrm{ksi}$. This strength is exceeded by the interlaminar shear. stresses in most of the specimen (fig. 4), indicating high probability of progressive delamination. The other composite systems exhibit similar behavior (ref. 11).

Transient finite-element analysis results for interlaminar shear stress. for the S-GL/EP composite are summarized in figure 5. The load-time trace (ref. 9) used for the impact force in the transient analysis and the static interlaminar shear strength are shown in the figure. The transient inter1 aminar shear stress exceeds the corresponding static strength near the impact and notch tip regions at early times of the impact event. This will.cause delaminations in these regions and corresponding load decreases in the loadtime trace. Additional delaminations will occur toward the center of the specimen as the impact load increases. The delaminated portions will more than likely behave as individual beams transmitting normal stress but not shear stress at the delaminated surfaces. The individual beams will continue to absorb energy until they fail in flexure. It is interesting to note that the significant, initial load drop in the load-time trace (fig. 5) is probably associated with the rapid displacement increase as the specimen delaminates into individual beams.

The important conclusion from the transient analysis results and discussion is that the transient (dynamic) interlaminar shear stresses can cause progressive delamination early in the impact event leading to subsequent individual layer beam action. This conclusion is consistent with conclusions made previously from the results of the mechanistic and statistical models.

\section{INDIVIDUAL-LAYER-BEAM BEHAVIOR AND FRACTURE PROGRESSION}

The individual-layer-beam behavior was evaluated in order to obtain a better assessment of the fracture progression during impact. The individuallayer-beam behavior was evaluated using finite-element and simple beam theory analyses. The finite-element analysis was used on a four-layer beam with progressively degraded interply layer modulus (E). The simple beam theory analysis was applied to a four-individual-iayer beam.

The results of the finite-element analysis are summarized in figure 6 . The bending deflection of the beam increases nonlinearly as the interlaminar layer modulus $E$ is progressively degraded. The equation describing the curve is shown in the figure. For the individual-layer-behavior limiting case $\left(E / E_{E P}=0\right)$ the bending deflection of the beam with the four individual layers is sixteen (16) times that of the undegraded composite beam. The curve in figure 6 is very significant since it shows substantial increases in the bending deflection as the interlaminar layer modulus degrades to 0.2 of its 
undegraded composite value. This will definitely increase the energy absorption considerably but will degrade structural integrity as assessed by deflection limits, buckling, and resonant frequencies.

The results of the simple beam theory analysis are summarized in figure 7 . The results are generalized to the behavior of a beam with $N$ individual layers as compared to a composite beam. The following are observed for the same load:

(1) The bending deflection and the work done (energy absorbed) increase as the square of the number of individual (delaminated) layers.

(2) The flexural stress in each individual layer increases as the number of individual beams increases.

(3) The interlaminar, or short beam shear (S.B.S.), stress is independent of the number of individual layers. This is very significant since progressive doubling of the individual-layer beams can occur by delamination without increase in the load.

(4) Progressive individual-layer-beam doubling will occur so long as the. interlaminar (S.B.S.) strength satisfies the inequality shown in the figure.

The finite-element transient analysis results and the individual layer beam analysis results can now be used to postulate dynamic fracture progression:

(1) Dynamic delamination occurs in one plane initially.

(2) The dynamic flexural stress in each individual layer will increase.

(3) Progressive doubling of delaminated layers will continue so long as the inequality in figure 7 is satisfied.

(4) The bending deflection and the external work done will increase progressively.

(5) The impact load will decrease during delamination because of displacement "jumps" as additional individual layers are formed.

(6) Intralayer flexural fracture will occur when the flexural stress equals or exceeds the corresponding strength.

(7) Specimen fracture will follow either by progressive intralayer flexural fracture or by combinations of progressive intralayer delamination and flexural fracture.

(8) The impact load will progressively decrease due to progressive deflection "jumps" if these jumps are relatively large (S-G/E) or remain level if these jumps are relatively small (HMS/E).

The impact load-time traces in figure 8 appear to corroborate, in part, the postulated fracture progression which is consistent with that hypothesized in reference 11. Needless to say, additional experimental data using instrumented impact and high-speed movies will be required to verify the postulated fracture progression.

\section{ENVIRONMENTAL. EFFECTS}

The environmental effects on impact resistance can be evaluated using the hygrothermomechanical theory (ref. 8). This is done by determining the environmental effects in the terms representing (1) the dominant energy mechanisms in the mechanistic model at the micromechanics level and (2) the interlaminar shear and flexural strengths which influence the fracture progression. 
Results of some general trends may be summarized as follows:

(1) The energy absorption prior to delamination will decrease when the hygrothermal environment degrades the interlaminar shear strength relative to a reference value and conversely.

(2) The impact load, prior to delamination, will be less when the interlaminar shear strength degrades and conversely.

(3) The total work done prior to fracture will increase when the hygrothermal environment (i) degrades the interlaminar shear strength at a faster rate than the flexural strength and (ii) has a relatively small effect on the tensile strength.

Specific applications need to be examined on an individual case basis. An illustrative example that may be used to assess the environmental effects on impact resistance is outlined in the appendix.

It is worth noting that extreme envirunments, which substantially degrade (1) the compression and shear moduli and (2) the transverse and longitudinal compression strengths, will change the impact resistance dramatically. These types of environments will probably change the relative significance of the contributions of the energy-absorbing mechanisms, especially that due to local indentation. The degradation of impact resistance at extreme hostile environments is academic, however. These hostile environments will also substantially degrade the structural integrity of the composite to make it impractical for structural applications.

\section{GENERALIZATIONS AND PROPOSED DEFINITIONS}

The collective results, attendant conclusions, and illustrative example for the impact resistance of unidirectional composites described herein should be applicable in assessing, or estimating, the impact behavior of angleplied laminates as well. The significant supporting reasons are: (1) the consistency of the theoretical results obtained from the three different methods (mechanistic model, statistical model; and transient finite-element analysis); (2) the excellent correlation of predicted results with measured data (mechanistic model - energy absorbed prior to onset of damage, statistical model total work done, transient analysis - delamination influence on impact load); (3) the inherent features of the Charpy impact specimen (interlaminar shear stress dominance, stress concentration at notch tip; highly localized impact (impact load point above notch tip), and delamination initiated fracture); (4) fracture progression (progressive delamination followed by flexural failure of the delaminated layers); and (5) the localized nature of impact in angleplied laminates is similar to Charpy impact near field behavior in terms of stress, energy-absorbing mechanisms, failure initiation, and fracture progression.

Considerable skepticism exists in the composites community (including the authors) of the significance of Charpy impact to angleplied laminate impact. The main reason for this skepticism is the difficulty associated in relating the impact energy absorbed in the angleplied laminate to that in the Charpy specimen. As is discussed herein, the local behavior needs to be assessed at several levels during the impact event. This way fundamental composite material characteristics, which lead to impact resistance (defined by energy absorption prior to delamination and subsequent fracture progression), are 
identified and quantified. As expected, fundamental composite material characteristics are not altered by the type of impact.

Considering the collective results and discussions of this investigation, the following working definitions are proposed for energy absorption mechanisms and energy-release mechanisms:

- Energy-absorption mechanisms are those composite micromechanics mechanisms through which composites continue to absorb impact energy while the impact load rises from a current value without any or additional damage, as observed in an impact load versus time trace (fig. 5).

- Energy-release mechanisms are those composite micromechanics mechanisms through which composites release impact energy. This release in energy is associated with sustained or progressive damage and corresponds to impact load leveling or decrease as observed in an impact load versus time trace (fig. 5).

Both of these definitions emanate from and are consistent with the notion that sustained and progressive damage reduce the structural integrity of a composite as measured by deflection and frequency response limits and buckling resistance.

Fracture surfaces related to fracture modes I, II, and III are thought to constitute or represent energy-absorption mechanisms during impact. However; released energy associated with these fracture surfaces is an integrated effect of the energy-absorbing micromechanics mechanisms just defined. Mode I, II, and III types of mechanisms are gross energy release mechanisms and, as such, do not represent fundamental material characteristics.

\section{SUMMARY OF RESULTS AND CONCLUSIONS}

The significant results and conclusions of an investigation on the impact resistance of unidirectional fiber composites, including energy-absorbing mechanisms and environmental effects, are now summarized:

1. Flexure and interlaminar shear deformations are the dominant energyabsorbing mechanisms during impact; the area under the linear stress-strain diagram represents the most significant contribution.

2. Fiber pullout, interply delamination, and local indentation are energyrelease mechanisms.

3. Interply delamination occurs early in the impact event.

4. Interply delaminations increase the deflection, external work, and flexural stress in the delaminated layers, but they decrease buckling resistance and vibration frequencies.

5. The external work in delaminated composites increases approximately as the square of the numbers of delaminated individual layers (beams) increases compared to the undelaminated composite.

6. Dynamic fracture during impact is a progression of interlaminar delaminations and intralayer fracture of the delaminated layers.

7. The environmental effects on impact resistance can be assessed using hygrothermomechanical theory.

8. The mechanical behavior of fiber composites under impact can be assessed using mechanistic models, statistical models, finite-element transient analysis, and available experimental data. 


\section{APPENDIX - ILLUSTRATIVE EXAMPLE OF ENVIRONMENTAL}

\section{EFFECTS ON IMPACT RESISTANCE}

The hygrothermal effects on impact resistance may be assessed using the following approach. First it is necessary to estimate the hygrothermal degradation effects on unidirectional composite properties which are resin dominated. This approach is briefly described below including a numerical example.

The hygrothermal degradation is estimated using the following equation (ref. 3):

$$
\frac{P_{H}}{P_{0}}=\left(\frac{T_{g w}-T}{T_{g d}-T_{0}}\right)^{1 / 2}
$$

where $P_{H}$ is the hygrothermally degraded property, $P_{0}$ a reference property, $T_{\mathrm{gw}}$ the glass transition temperature of the wet resin, $T_{\text {gd }}$ the glass transi$t$ ion temperature of the dry resin, $T$ the temperature at which. $P_{H}$ is needed, and $T_{0}$ the reference temperature corresponding to $P_{0}$. The dominant energy absorbing mechanism $\left(S_{\ell}^{2} 11 T / E_{\ell 11}\right)$ is fiber dominated. However, the interlaminar shear $\left(S_{\ell 12 S}\right)$ and flexural $\left(S_{\ell 11 F}\right)$ strengths, which control delaminations and fracture progression, are resin dominated. The flexural strength is resin dominated through longitudinal compression as given by the following equation (ref. 12):

$$
S_{\ell 11 F}=\frac{3 S_{\ell 11 C}}{1+\frac{S_{\ell 11 C}}{S_{\ell 11 T}}}
$$

where $S_{\ell 11 F}$ is the longituding flexural strength, $S_{\ell 11 C}$. the longitudinal compression strength, and $S_{\ell 11 T}$ the longitudinal tensile strength.

As a numerical example, consider the hygrothermal effects on the dynamic fracture progression of a Charpy specimen made from S-glass/epoxy composite with the following properties:

$$
\begin{aligned}
& T_{g w}=350^{\circ} \mathrm{F} \\
& T_{g d}=420^{\circ} \mathrm{F} \\
& T^{\prime}=200^{\circ} \mathrm{F} \\
& T_{0}=70^{\circ} \mathrm{F}
\end{aligned}
$$

$$
\begin{aligned}
& S_{\ell 11 T o}=222 \mathrm{ksi} \\
& S_{\ell 11 \mathrm{Co}}=180 \mathrm{ksi} \\
& S_{\ell 12 S_{0}}=14 \mathrm{ksi}
\end{aligned}
$$

Using these numerical values in equations $(A-1)$ and $(A-2)$ we obtain the following:

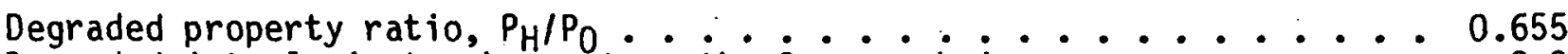

Degraded interlaminate shear strength, $S_{l} 11 \mathrm{SH}, \mathrm{ksi} \ldots . . . . . . . .2$

Degraded flexural strength, $S_{\ell 11 F H}$, ksi . . . . . . . . . . . . 231

Degraded longitudinal compression strength, $\mathrm{S}_{\ell 11 \mathrm{CH}}, \mathrm{ksi} \ldots . . \ldots 118$

Undegraded flexural strength, $S_{\ell 11 F 0, k s i} \ldots . . . . . . . . .298$ 
The interlaminar shear strength was degraded. Therefore, the impact load to initial damage will be reduced. The degraded ratio of the interlaminar shear and flexural strengths relative to reference values are, respectively,

$$
\begin{aligned}
& S_{\ell 12 S H} / S_{\ell 12 S 0}=0.655 \\
& S_{\ell 11 F H} / S_{\ell 11 F 0}=0.775
\end{aligned}
$$

The interlaminar shear strength degrades at a faster rate than the flexural strength since the longitudinal tensile strength is fiber dominated and thus not affected. Therefore, the work done to fracture will increase relative to the reference value. This example illustrates that it is not intuitively apparent what effects the environment has on peak load or total work to fracture. This example also illustrates the advantage of having formal procedures, even if approximate, to assess complex composite behavior such as impact.

\section{REFERENCÉS}

1. Chamis, C. C., Hanson, M. P. and Serafini, T. T., in Composite Materials: Testing and Design (Second Conference), ASTM STP 497, American Society for Testing and Materials, 1972, pp. 324-349.

2. Broutman, L. J. and Rotem, A., in Foreign Object Impact Damage to Composites, ASTM STP 568, American Society for Testing and Materials, 1975, pp.114-133.

3. Yeung, P. and Broutman, L. J., Polymer Engineering and Science, Vo1. 18, No. 2, Mid-Feb. 1978, pp. 62-72.

4. Sun, C. T. and Wang T., "Dynamic Responses of a Graphite/Epoxy Laminated Beam to Impact of Elastic Spheres," NASA CR 165461, National Aeronautics and Space Administration, Washington, D.C., Sept. 1982.

5. Chamis, C. C., Hanson M. P. and Serafini, T. T., "Designing for Impact Resistance with Unidirectional Fiber Composites," NASA TN D-6463, National Aeronautics and Space Administration, Washington, D.C., Aug. 1971.

6. Chamis, C. C. and Smith, G. T., "Environmental and High-Strain Rate Effects on Composite for Engine Applications," NASA TM-82882, National Aeronautics and Space Administration, Washington, D.C., May 1982.

7. Sun. C. T. and Yang, S. H., "Contact Law and Impact Responses of Laminated Composites," NASA CR-159884, National Aeronautics and Space Administration, Washington, D.C., Feb. 1980 .

8. Chamis, C. C., Lark, R. F. and Sinclair, J. H., in Advanced Composite Materials-Environmental Effects, ASTM STP 658, American Society for Testing and Materials, 1978, pp. 160-192.

9. Friedrich, L. A. and Preston, J. L., Jr., "Impact Resistance of Fiber Composite Blades Used: in Aircraft Turbine Engines," NASA CR-134502, National Aeronautics and Space Administration, Washington, D.C:, May 1973. 
10. Sidik, S. M., "An Improved Multiple Linear Regression and Data Analysis Computer Program Package," NASA TN D-6770, National Aeronautics and Space Administration, Washington, D.C., Apr. 1972.

11. Chamis, C. C., "Failure Mechanics of Fiber Composite Notched Charpy Specimens," NASA TM $X-73462$, Nationa! Aeronautics and Space Administration, Washington, D.C., Sept. 1976.

12. Sinclair, J. H. and Chamis, C. C., "Compression Behavior of Unidirectional Fibrous Composites," NASA TM-82833, National Aeronautics and Space Administration, Washington, D.C.:. Mar. 1982. 
TABLE 1. - CONSTITUENT MATERIAL AND COMPOSITE PROPERTIES ${ }^{a}$

\begin{tabular}{|c|c|c|c|c|c|c|}
\hline \multirow{2}{*}{ Property } & \multicolumn{6}{|c|}{ Composite } \\
\hline & MOD-11/EP & MOD-1/EP & T75/EP & $B / E P$ & $S-G L / E P$ & KEV/EP \\
\hline Fiber diameter, $d_{f}$, in. & 0.0003 & 0.0003 & 0.0003 & 0.004 & 0.00036 & 0.00045 \\
\hline $\begin{array}{l}\text { Sft, ksi } \\
\text { Fiber volume ratio, FVR }\end{array}$ & $\begin{array}{r}350 \\
0.55\end{array}$ & $\begin{array}{r}250 \\
0.53\end{array}$ & $\begin{array}{r}345 \\
0.59\end{array}$ & $\begin{array}{r}460 \\
0.55\end{array}$ & $\begin{array}{r}670 \\
0.59\end{array}$ & $\begin{array}{r}400 \\
0.63\end{array}$ \\
\hline $\begin{array}{l}\text { Composite longitudinal } \\
\text { modulus, } \mathrm{E}_{\ell} 11,10^{6} \mathrm{psi}\end{array}$ & 18.9 & 31.3 & 39.2 & 31.5 & 7.2 & 13.2 \\
\hline $\begin{array}{l}\text { Composite shear modulus, } \\
G_{\ell 12} 10^{6} \text { psi } \\
\text { Composite longitudinal }\end{array}$ & 0.66 & 0.64 & 0.48 & 0.96 & 0.83 & 0.27 \\
\hline $\begin{array}{c}\text { strength, } S_{l} 11 T, \text { ksi } \\
\text { Composite S.B.S. strength, }\end{array}$ & 161 & 129 & 154 & 222 & 222 & 170 \\
\hline $\begin{array}{l}S_{\ell 12 S}, \mathrm{ksi} \\
\text { Charpy impact eneray, CIE. }\end{array}$ & 10.3 & 8.4 & 7.8 & 8.5 & 14 & 6.9 \\
\hline$f t-1 b$ & 6.5 & 2.4 & 3.0 & 8.5 & 35 & 13.0 \\
\hline
\end{tabular}

aComposite properties generated by Pratt \& Whitney under NASA Contract NAS 3-15568. 
TABLE II. - MECHANISTIC MODEL - EXPERIMENTAL DATA CORRELATION
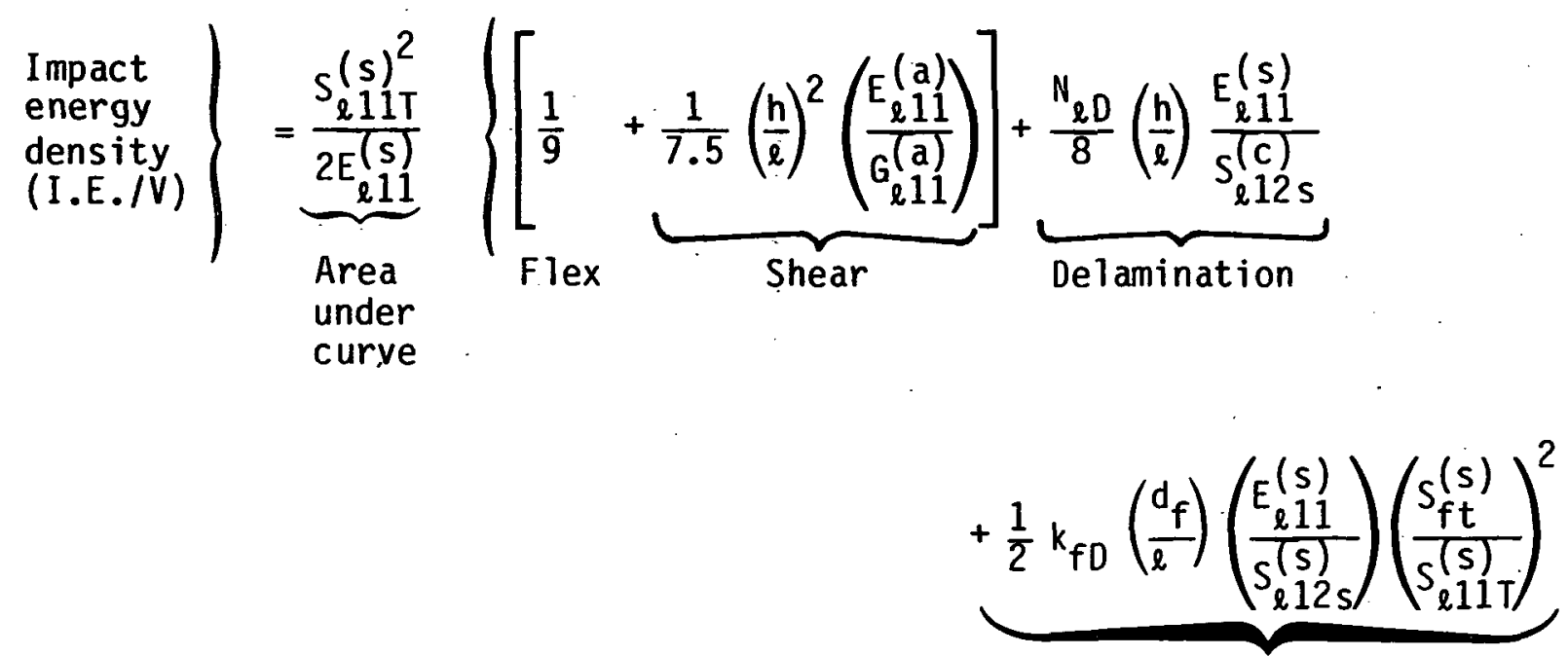

Fiber pullout

\begin{tabular}{|l|c|r|}
\hline \multicolumn{2}{|c|}{ Term } & \multicolumn{2}{|c|}{ Composite } \\
\cline { 2 - 3 } & MOD-1/EP & S-GL/EP \\
\hline Measured impact energy, ft-lb & 2.4 & 35 \\
Volume, V, in.3 & 0.220 & 0.220 \\
Area under curve, aug, in. ${ }^{2}$ & 266 & 3420 \\
Flex & 0.111 & 0.111 \\
Shear & 0.396 & 0.072 \\
Delamination, DEL (1 layer) & 116.6 & 16.1 \\
Fiber pullout, FP0 & 0.207 & 0.211 \\
Computed impact energy, ft-1b: & 572 & 1034 \\
All terms & 2.47 & 11.47 \\
Flex and shear & \\
\hline
\end{tabular}




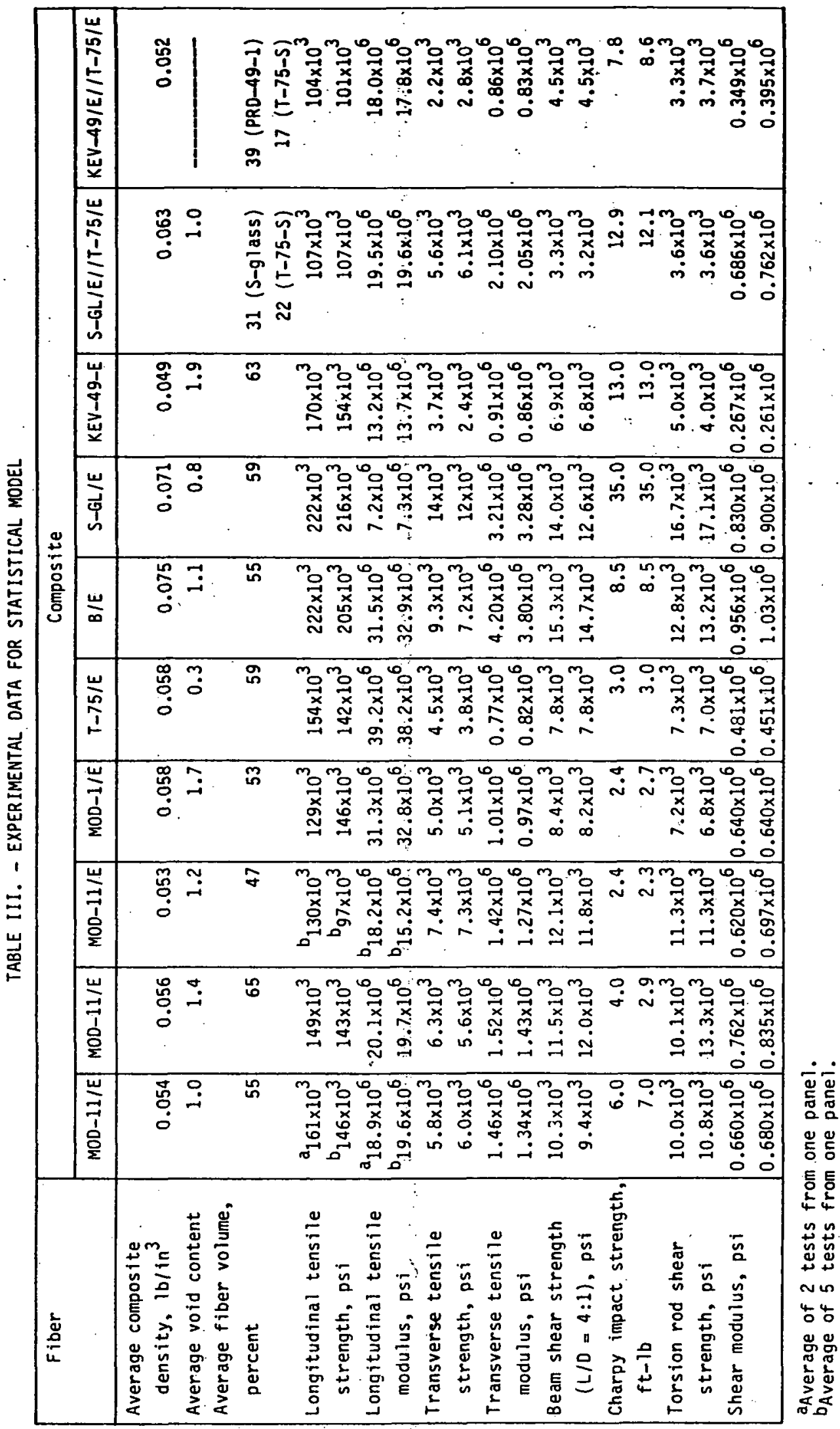


TABLE IV. - CORRELATION OF STATISTICAL MODEL WITH EXPERIMENTAL

DATA FOR UNIDIRECTIONAL COMPOSITES

\begin{tabular}{|l|c|c|c|c|}
\hline \multirow{2}{*}{ Composite } & \multicolumn{2}{|c|}{ Longitudinal properties } & \multicolumn{2}{c|}{ Charpy impact, ft-lb } \\
\cline { 2 - 5 } & $\begin{array}{c}\text { Strength, } \\
\text { ksi }\end{array}$ & $\begin{array}{l}\text { Modulus, } \\
10^{6} \mathrm{psi}\end{array}$ & Measured & Predicted \\
\hline MOD-11/EP & 153 & 19.2 & 6.5 & 6.5 \\
MOD-1/EP & 129 & 31.3 & 2.4 & 2.8 \\
T75/EP & 148 & 38.7 & 3.0 & 3.0 \\
B/EP & 222 & 31.5 & 8.5 & 8.2 \\
S-GL/EP & 219 & 7.2 & 35.0 & 35.0 \\
KEV/EP & 170 & 13.2 & 13.0 & 11.6 \\
MOD-11/POLY & 183 & 21.3 & 6.5 & 8.4 \\
S-GL/E, T75/E, S-GL/EP & a 219 & 19.5 & 12.5 & 13.0 \\
KEV/E,T75/E, KEV/EP & a170 & b 17.9 & 8.2 & 8.6 \\
\hline
\end{tabular}

aComposite shell strength.

bybrid composite modulus. 


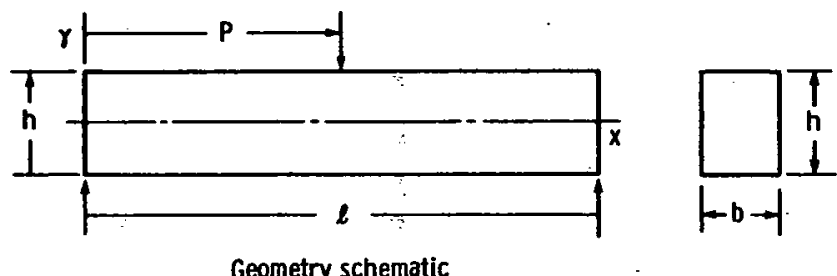

Mechanistic model for elastic energy:

$$
\begin{aligned}
& \text { IED }=\frac{S^{(s)^{2}}}{2 F_{\ell l 1}}\left\{\left[\frac{1}{9}+\frac{1}{7.5}\left(\frac{h}{\ell}\right)^{2}\left(\frac{E_{\ell 11}^{(a)}}{G_{\ell l 1}^{(a)}}\right)\right]+\frac{N_{\ell D}}{8}\left(\frac{h}{l}\right)\left(\frac{E_{\ell l 1}^{(s)}}{S_{\ell 12 s}^{(c)}}\right)\right. \\
& +\frac{1}{2} k_{f D}\left(\frac{d_{f}}{\ell}\right)\left(\frac{E_{\ell 11}^{(s)}}{(s)}\right)\left(\frac{s_{f t}^{(s)}}{s_{\ell 11 T}^{(s)}}\right)^{2} s_{\ell l \underline{T}}^{2}+\quad \text { inelastic energy }
\end{aligned}
$$

Figure 1. - Simple beam schematic and mechanistic model.

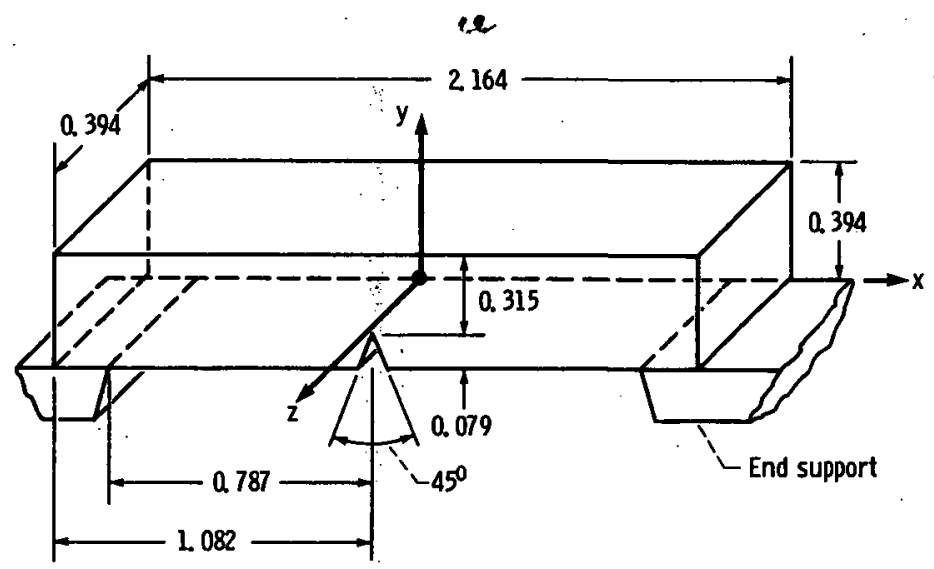

Figure 2 - Charpy test specimen schematic. (All dimensions are in inches.) 


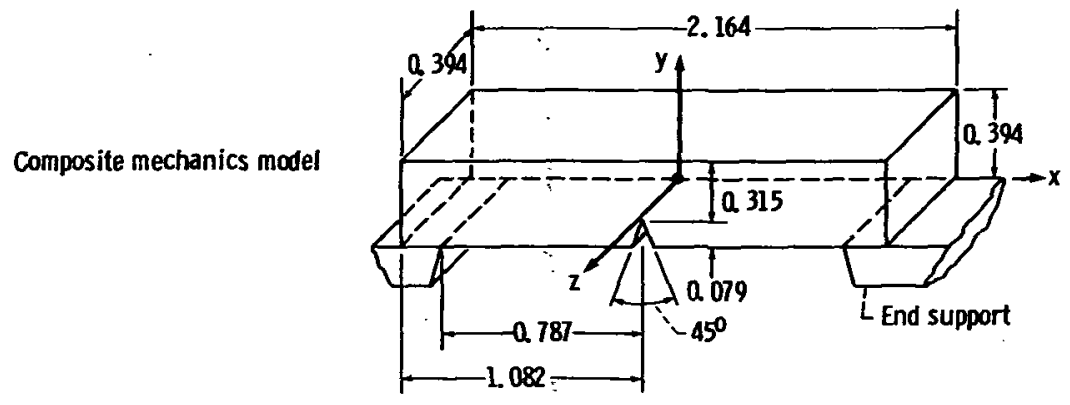

$$
\begin{aligned}
& \left\{\begin{array}{l}
\text { Charpy } \\
\text { impact }
\end{array}\right\}=c_{1} \frac{s_{\ell 11 T}^{2}}{E_{\ell 11}}+c_{2} \frac{s_{\ell l 1 T}^{2}}{c_{\ell 12}}+c_{3} \frac{s_{\ell 11 T}^{2}}{s_{\ell 12 s}}+c_{4} \frac{s_{\ell 11 T}^{2}}{k_{l}^{2} s_{\ell 12 s}}+c_{5} \frac{s_{\ell 22 T}^{2}}{E_{\ell 22}}
\end{aligned}
$$

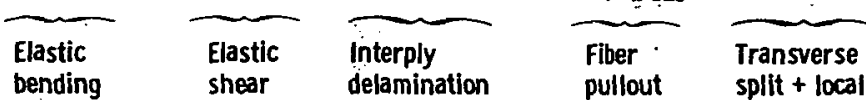

$$
\begin{aligned}
& \text { bending shear delamination pullout split }+ \text { local }
\end{aligned}
$$

Figure 3. - Simple beam schematic, statistical model, and correlation. This model with regression analysis and with experimental data ranging from HM/EP to S-GLIEP yielded Charpy impact 5. $3 \times 10^{-3} \mathrm{~S}_{\ell 11 \mathrm{~T}}^{2} \mathrm{E}_{\ell 11}$ (in $\mathrm{ft}-\mathrm{lb}$ ) with correlation coefficient of 0.994 

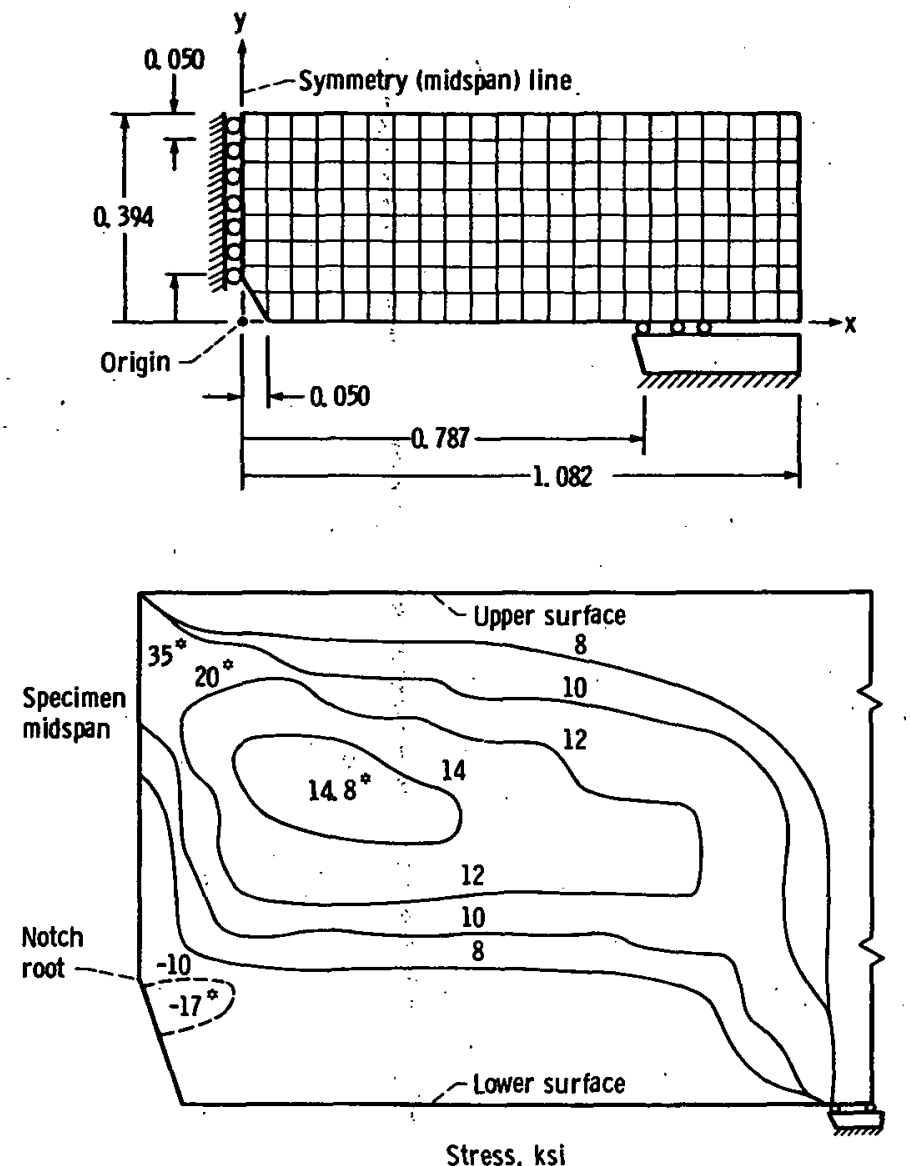

Figure 4. - Finite-element model and interlaminar shear stresses. Finite-element statistics: nodes, 197; D. O. F. Inode, 2; elements, 168; location of stress value, *. 


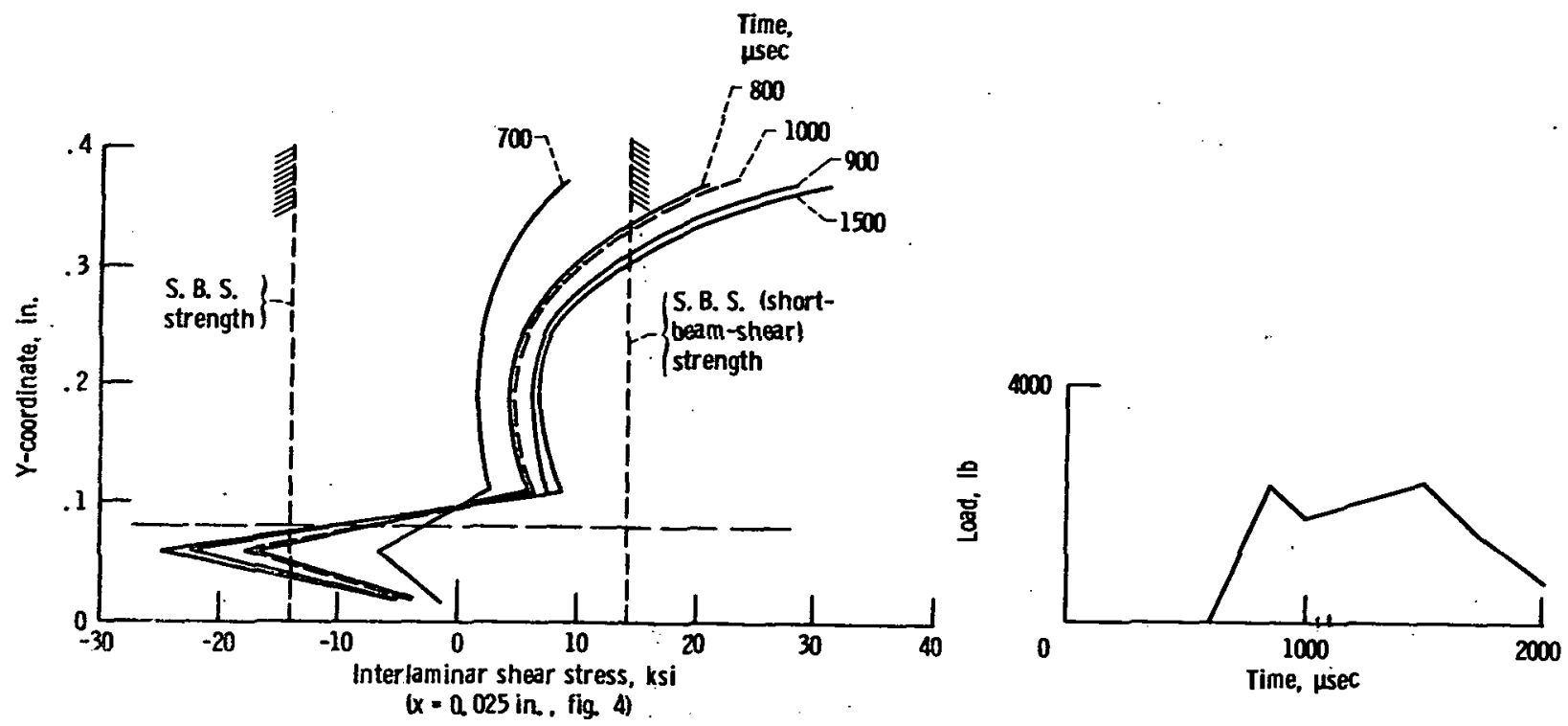

Figure 5 - Transient finite-element analysis results.

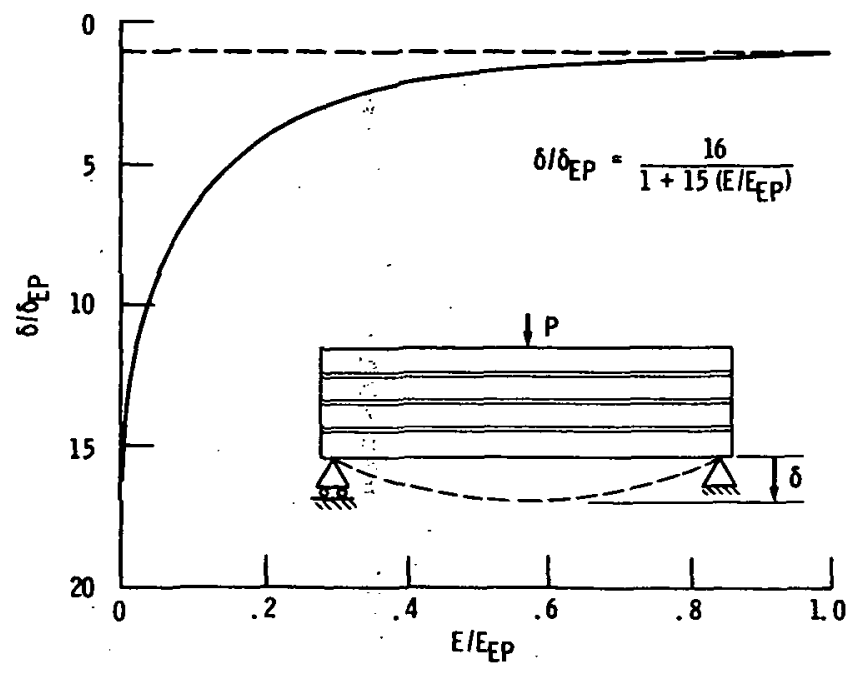

Figure 6. - Bending deflections of beam with progressively degraded interlaminar layer modulus. 


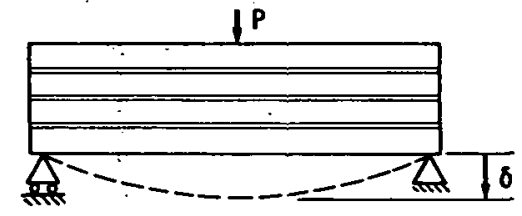

$\begin{array}{ll}\text { Deflection: } & \sigma_{\mathrm{N}} / \delta_{\mathrm{C}}=\mathrm{N}^{2} \\ \text { Work done: } & W_{\mathrm{N}} / W_{\mathrm{C}}=\mathrm{N}^{2} \\ \text { Flexural stress: } & \sigma_{\mathrm{FN}} / \sigma_{\mathrm{FC}}=\mathrm{N} \\ \text { S. B.S. stress: } & \sigma_{\mathrm{SN}} / \sigma_{\mathrm{SC}}=1 \\ \text { "Assured" delamination: } & \mathrm{S}_{\mathrm{SC}}<\mathrm{N} / 2 \mathrm{~h} / \mathrm{l} \mathrm{S}_{\mathrm{FC}}\end{array}$

Figure 7. - Effects of simulated individual layer behavior on bending.
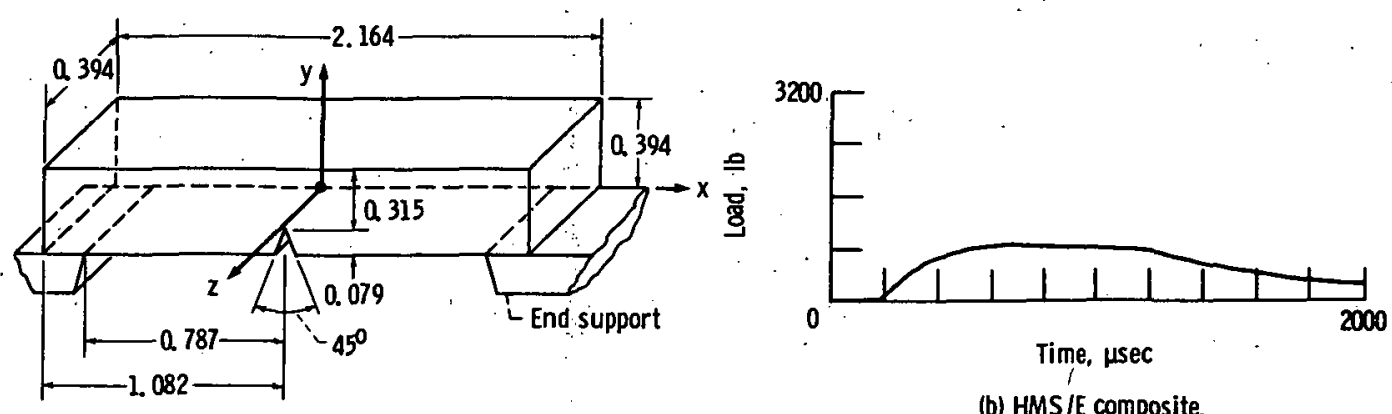

(a) Test specimen geometry. (All dimensions are in inches.)

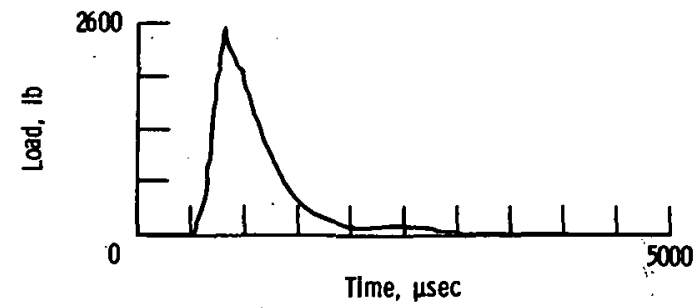

(c) ASIE composite.

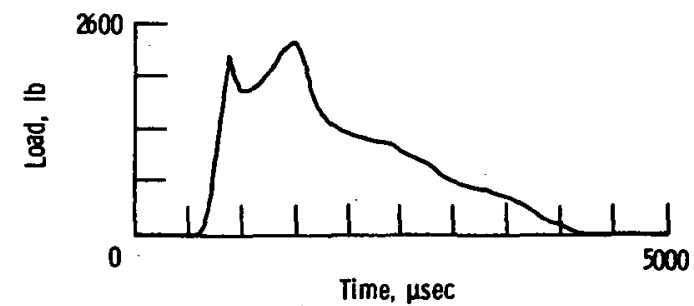

(d) S-G/E composite.

Figure 8 - Charpy specimen impact load-time traces (ref. 9). 


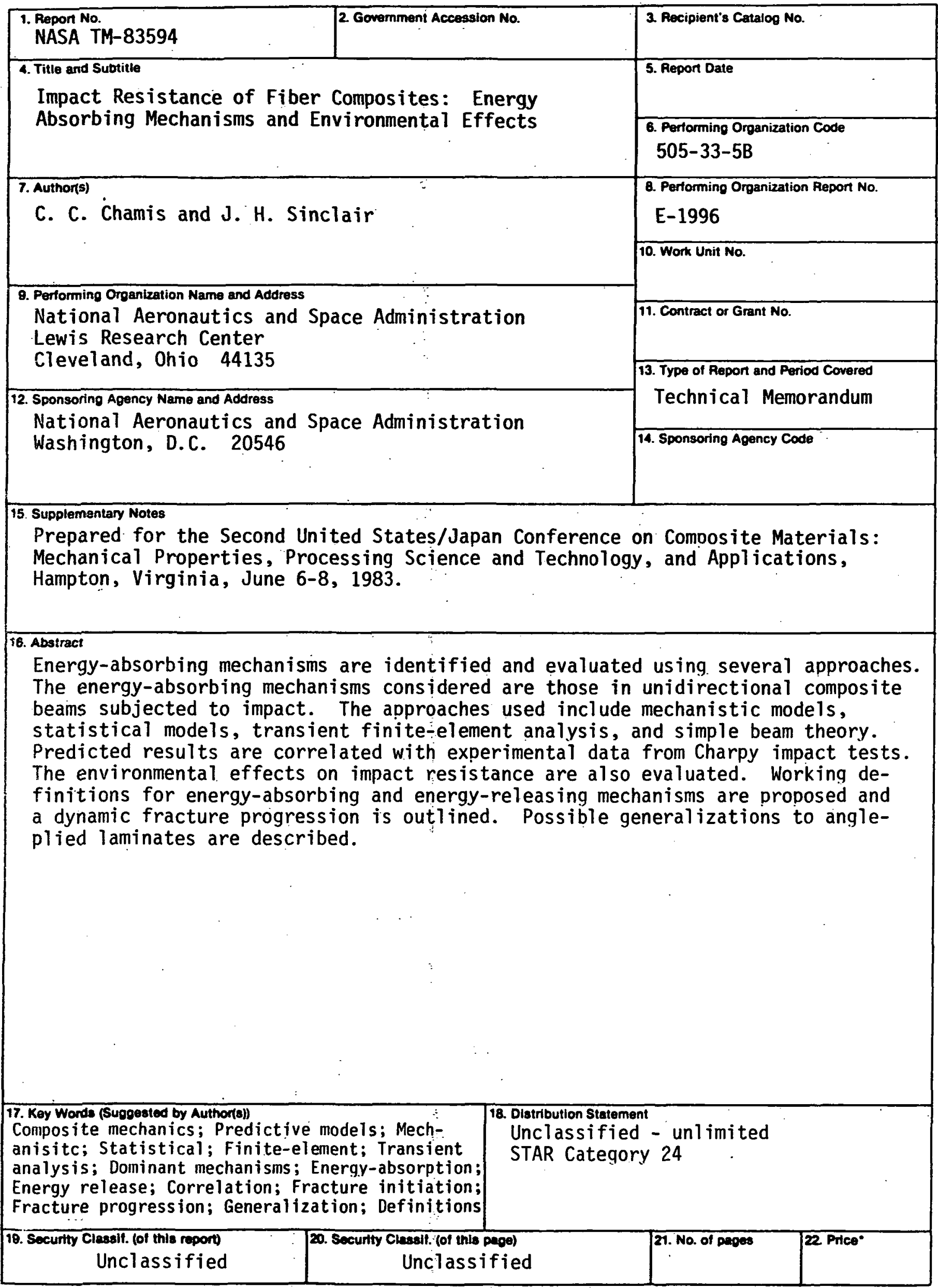

-For sale by the National Technical Information Service. Springfield. Virginia 22161 
National Aeronautics and

Space Administration

\section{Washington, D.C.}

20546

Official Business

Penalty for Private Use, $\$ 300$ enccial föratu class mail book

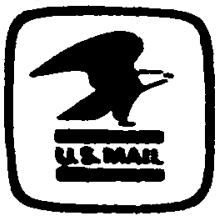

Postegs and Fees Paid

Netional Aeroneutics and

Spece Administration

NASA-451 